\title{
Rehabilitation and Esthetic Enhancement of Edentulous Patient with Hollow Cheeks Using Innovative Detachable Cheek Plumper: Case Report
}

\author{
Manu Rathee, Divakar S, Sanju Malik, Poonam Wakure, and Sujata Chahal
}

\section{ABSTRACT}

Complete edentulism for longer period of time and aging causes flaccid of facial musculature which leads to sunken cheeks and unpleasing appearance of face. In order to get a supplemental support for the drooping cheek muscles, fabrication of conventional complete denture with adjunct detachable cheek plumpers are simple, acceptable noninvasive and economical. Despite the discussion of various attachment used for cheek plumper in literature each have their own disadvantages. The present clinical report demonstrated the use of chairside available lingual sheath and stainless steel wire for the attachment of cheek plumpers to the maxillary complete denture.

Keywords: Cheek plumper, Esthetics, Lingual sheath, Sunken/hollow cheeks, Stainless steel wire.

\section{INTRODUCTION}

Geriatric patients usually suffers from partial or complete edentulism, ridge resorption, loss of vertical dimension and reduced muscle tone. It leads to reduced lower face height shrunken cheeks, wrinkling and drooping appearance of face. In addition to dental factors, aging process, change in diet, personal habits, systemic health of patient further degrades the esthetics of the patient [1].

According to the investigation by Peltzer et al, the prevalence rate of edentulism among older individuals in India is $16.3 \%$. The most common rehabilitative treatment options for such patient is removable complete denture fabrication. But the conventional complete denture fails to meet the requirements of patients with slumped cheeks and lips. To overcome these limitations cheek plumpers or cheek lifting appliances were introduced [2].

Sunken cheeks are due to loss of subcutaneous fat of the face most commonly below the zygomatic bone which gives an undesirable facial esthetics with facial fold and indentations. It affects patient self-esteem and having a
Published Online: December 04, 2021

ISSN: $2684-4443$

DOI: $10.24018 /$ ejdent.2021.2.6.123

Manu Rathee

Department of Prosthodontics, Post Graduate Institute of Dental Sciences, Rohtak, Haryana, India.

(e-mail: ratheemanu@ gmail.com)

Divakar S*

Department of Prosthodontics, Post Graduate Institute of Dental Sciences, Rohtak, Haryana, India.

(e-mail: divakarsanthanam17@gmail.com) Sanju Malik

Department of Prosthodontics, Post Graduate Institute of Dental Sciences, Rohtak, Haryana, India.

(e-mail: smsanju201@gmail.com)

Poonam Wakure

Department of Prosthodontics, Post Graduate Institute of Dental Sciences, Rohtak, Haryana, India.

(e-mail: drpoonamwakure@ gmail.com) Sujata Chahal

Department of Prosthodontics, Post Graduate Institute of Dental Sciences, Rohtak, Haryana, India.

(e-mail: Sujata.chahal1@gmail.com)

*Corresponding Author

feeling of social exclusion. Cheek plumpers or cheek lifting appliances with conventional complete denture rehabilitate as well improves the esthetics by lifting the slumped cheeks and lip [3].

The conventional cheek lifting appliances are made by adding thickness to the buccal flange of maxillary complete denture but it increases the heaviness and compromise the retention and stability. Continuous stretching of shrunken cheek muscles by such denture may lead to muscle spasm. Adjustable cheek plumbers are more commonly used which facilitates easy removal of cheek plumper and self-placement by the patient and helps in easy maintainance [4], [5].

This case report present with a novel approach of adjustable check plumpers using lingual sheath and stainless steel wire for attaching and detaching it from the maxillary denture.

\section{CASE REPORT}

A 86-year-old male patient reported to the Department of Prosthodontics with a chief complaint of difficulty in 
masticating food due to missing upper and lower teeth associated with sunken cheeks for 6 months.

\section{A. Examination}

On systemic examination, patient was debilitated and diabetic under medication for 12 years. Extraoral examination revealed poor esthetics, severely sunken lips and cheeks with wrinkled skin and unsupported cheek musculature (Fig. 1). On intraoral examination, the patient was completely edentulous of maxillary and mandibular arches with slightly resorbed alveolar ridge. Patient was an old denture wearer for 10 years which became loose and also not satisfactory with esthetics. Hence, fabrication of maxillary and mandibular complete dentures with lingual sheath and stainless steel wire retained detachable cheek plumpers attached to the buccal flange of maxillary denture was planned.
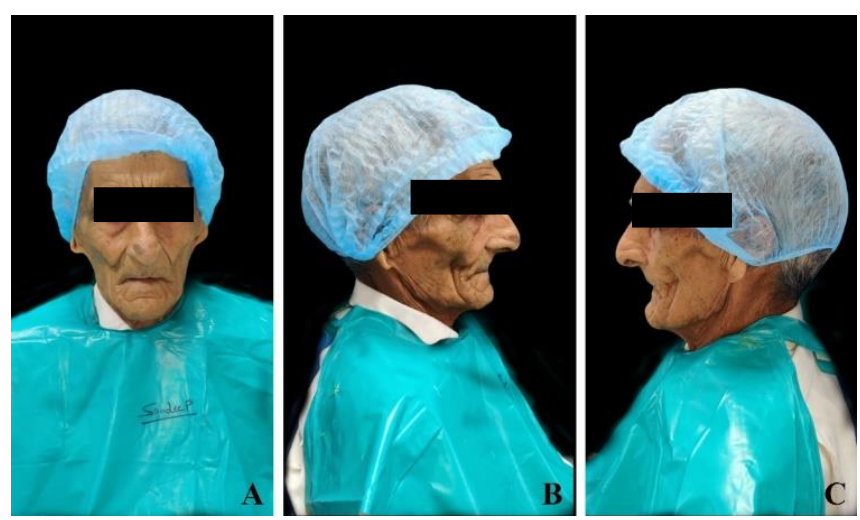

Fig. 1. Pre-rehabilitative view A) Frontal view. B) Left lateral view. C) Right lateral view.

\section{B. Clinical Procedures}

Since the patient debilitated, early appointment was given. Primary impressions of maxillary and mandibular edentulous arches are made using modelling plastic impression compound (Pinnacle Impression Compound; Dental Products of India). The primary cast was poured with dental plaster (Kaldent dental plaster; Kalabhai Karson Pvt Ltd.) and custom trays were made using autopolymerising resin (DPIRR cold cure; Dental Products of India) over it. Border molding was done using green stick impression compound (Pinnacle Tracing Sticks; Dental Products of India) and secondary impression using light body addition silicone elastomeric impression material (Avuegum Light body; Dental Avenue). The master cast was poured using dental stone (labstone dental plaster; Kalabhai Karson Pvt Ltd.) over which a denture base with occlusal rims were fabricated. Maxillomandibular jaw relation was recorded followed by articulation of maxillary and mandibular casts in a mean value articulator and teeth arrangement was done (Fig. 2).

After evaluation of the maxillary and mandibular teeth arrangement, cheek plumpers made of modelling wax (DPI modelling wax; Dental Product of India) were attached over the buccal flange of the maxillary denture near 1st premolar to 2nd molar region and inspected extra orally for acceptable cheek support, contour and interference with masticatory movements and facial muscular strain and spasm (Fig. 3).
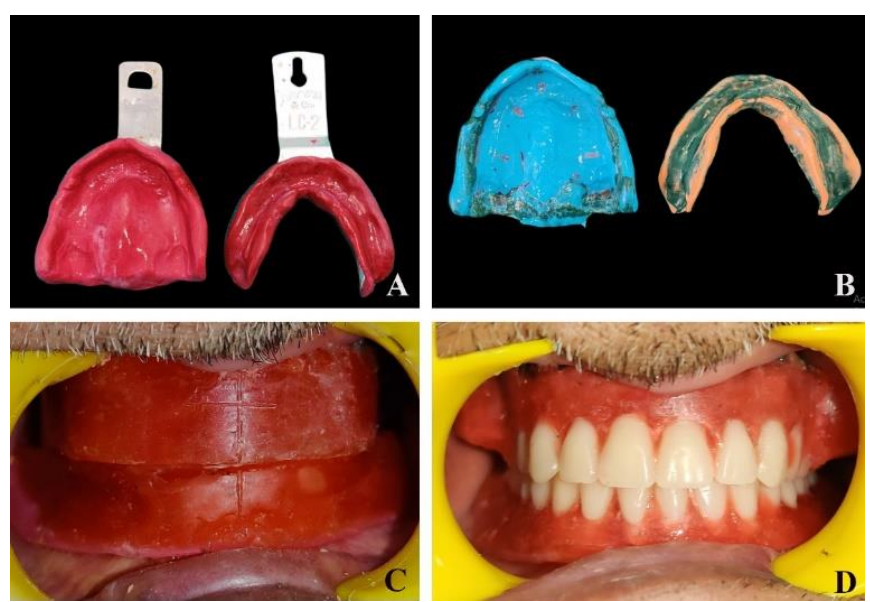

Fig. 2. Clinical procedure A) Primary impression. B) Secondary impression. C) Maxillomandibular jaw relation.
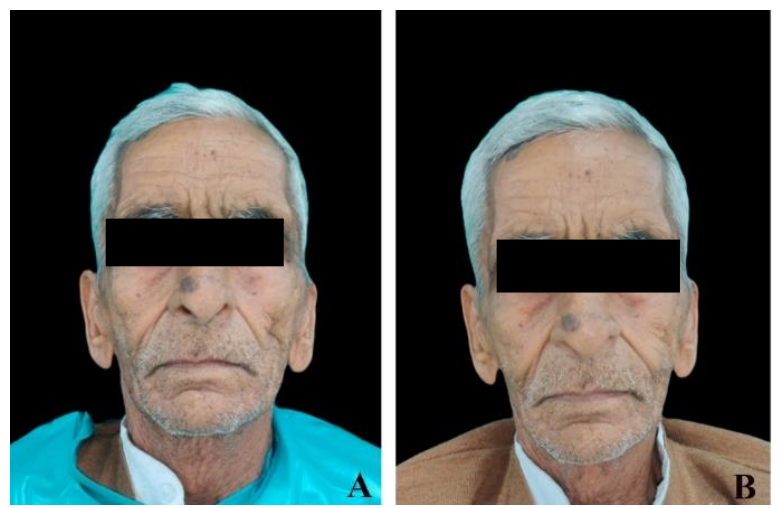

Fig. 3. Trial dentures with wax patterns for maxillary cheek plumpers attached. A) Right side (arrow indicate the presence of sunken cheek remains on side where cheek plumper is not made) B) Both sides.

\section{Laboratory Procedures}

The definitive denture and cheek plumper were fabricated from heat polymerising acrylic resin (DPI heat cure; Dental Product of India) by the process of flasking, dewaxing and polymerisation followed by trimming, finishing, and polishing of the denture and plumpers were done. Two slots on either side were made on the buccal flanges of the maxillary denture and corresponding area of cheek plumpers. The angulations and location of the lingual sheath and stainless steel wire were evaluated so that there will be no discrepancy and the stainless steel wire are bended to have a precise fit and easily seated in their respective sheaths. Lingual sheath (male counterpart) were sealed on buccal flange and 20 gauge stainless steel wire (female counterpart) were sealed on inner surface of cheek plumper using autopolymerising acrylic resin. After the resin was set, the plumper was removed. Trimming and polishing of the irregular surfaces were done and the prosthesis was delivered (Fig. 4, 5).

\section{Post-rehabilitative Instructions}

Patient was educated regarding the oral hygiene and denture cleaning practices. Instructions for attachment and detachment of cheek plumpers was given to the patient. Patient was called on regular follow up of 1st week, 1st and th month. Patient was satisfied in both function and esthetics of the delivered prosthesis(Fig. 6). 



Fig. 4. Laboratory procedures. A) Male component (Lingual sheath). B) Female component (stainless steel wire). C) Polymerized denture and cheek plumpers. D) Both components are sealed on their respective sites using



Fig. 5. Definitive prosthesis in-situ. A) Without cheek plumper. B) With cheek plumper.


Fig. 6. A) Pre-rehabilitative view. B) Post-rehabilitative view with denture. C) Post-rehabilitative view with denture and cheek plumber.

\section{DISCUSSION}

Cheek or buccal mucosa forms the lateral wall of the human mouth and supported anteriorly by the chiasma of facial muscle called modioli and posteriorly by molars and its adjacent structures, superiorly by malar bone and inferiorly by mandibular bone. The buccal pad of fat and subcutaneous fat provides supplemental support giving a soft spherical outline of cheek in the inferior one third of the face [6]. Hollow cheeks are attributed mainly due to the aging process and also occur due to diet, illness, environmental and personal habits leading to unpleasing appearance to the person.

In this contemporary world, it is very difficult to harmonize the artificial prosthesis to the natural tissues and obtain patient satisfactory. It is our responsibility to fulfill the need of the patient, who needs to recontour their lost facial appearance which helps to increase the patient psychological impact and self esteem [7], [8].

Complete denture with cheek plumpers is a better treatment option for patient with sunken cheeks. Conventional cheek plumpers were bigger in size, shape and difficulty in position. To overcome these drawbacks detachable cheek plumpers were introduced [9], [10].

In this case, heat cure autopolymerising resin was used to make cheek plumpers because it has more advantages than self cure autopolymerising resin in terms of colour, durability, and flexural strength. Due to the limited size, we fabricated the traditional detachable cheek plumbers. If there is increased weight of the prosthesis, in such situation hollow cheek plumpers can be made.

Various materials used for attachments of cheek plumpers to dentures are magnets [9], [11], push buttons or press stud [9], double dowel pins [1], friction locks [6], and customized $\mathrm{Co}-\mathrm{Cr}$ attachments [12]. However, each has their own limitations other than common disadvantages like food accumulation and heaviness (Table 1).

TABLE I: LIMITATIONS OF VARIOUS MATERIALS USED FOR ATTACHMENTS OF CHEEK PLUMPERS [6], [9], [12], [13]

\begin{tabular}{|c|c|c|}
\hline S.NO & Attachments & Limitations \\
\hline \multirow[t]{5}{*}{1.} & Magnets & Loss of magnetic power \\
\hline & & 2. $\begin{array}{l}\text { Susceptibility to tarnish \& } \\
\text { corrosion }\end{array}$ \\
\hline & & Gives bitter taste \\
\hline & & 4. Increased weight \\
\hline & & $\begin{array}{l}\text { 5. Risky in patients with cardiac } \\
\text { artificial pacemakers and } \\
\text { defibrillators (NdFeB magnets) }\end{array}$ \\
\hline \multirow[t]{3}{*}{2.} & Buttons or studs & Breakage \\
\hline & & 2. Susceptibility to corrosion \\
\hline & & $\begin{array}{l}\text { 3. Medically not approved for usage } \\
\text { in oral cavity }\end{array}$ \\
\hline \multirow[t]{2}{*}{3.} & Customized Co- & Difficult in fabrication \\
\hline & $\mathrm{Cr}$ attachments & Increased weight \\
\hline \multirow[t]{2}{*}{4.} & $\begin{array}{l}\text { Friction lock } \\
\text { attachments }\end{array}$ & $\begin{array}{l}\text { 1. Reduced retention over time } \\
\text { peroid }\end{array}$ \\
\hline & & 2. Difficult in fabrication \\
\hline
\end{tabular}

Lingual sheath and 20 gauge stainless steel wire was used as attachments for cheek plumpers in this case as it is readily available, cost effective, less weight, ease in placement and removal, snap fit, corrosion resistance and hence can be customized on the basis of size of plumper. But this technique might have disadvantages like difficulty in angualtion of components and chances of breakage of wire as they are embedded in resin. After 6 months of follow up, the 
attachments were retentive and patient was satisfied with the prosthesis. However long-term research is needed to know its success and longitivity.

\section{CONCLUSION}

Hollow or sunken cheeks can be rectified either by invasive and non-invasive methods. The invasive methods includes reconstructive cosmetic surgery, botulinum injection in the facial muscles to reduce muscle spasms and facial wrinkles. But these methods are expensive and time consuming and the outcome is temporary with more chances for relapse, postsurgical scar, skin allergic reactions and irritation. The most simple non invasive method for rectifying sunken cheeks is detachable cheek plumpers. The attachments should be low-cost, resistant to plumper rotation or movement while in use, and long-lasting. It will also stabilize the drooping facial muscles and improve its function and facial esthetics. In this case report, the various attachments available for cheek plumpers and its drawbacks were discussed and a novel technique of cheek plumper attachment was proposed along with its pros and cons to improve the patient's comfort, appearance and self confidence in society.

\section{REFERENCES}

[1] Pudi S, Kota S, K V G Ch K, Kaladi SR, Gade RR. An Innovative Technique Using a Stainless Steel Double Die Pin Retained Cheek Plumper in Complete Denture Esthetics: A Case Report. Cureus, 2019;11(11):e6197.

[2] Keni NN, Aras MA, Chitre V. Customised attachments retained cheek plumper prosthesis: a case report. J Indian Prosthodont Soc., 2012;12(3):198-200.

[3] Peltzer K, Hewlett S, Yawson AE, et al. Prevalence of loss of all teeth (edentulism) and associated factors in older adults in China, Ghana, India, Mexico, Russia and South Africa. Int J Environ Res Public Health, 2014;11(11):11308-11324.

[4] Keni NN, Aras MA, Chitre V. Customised attachments retained cheek plumper prosthesis: A case report. J Indian Prosthodont Soc, 2012 Sep 1;12(3): 198-200.

[5] Deogade SC. Magnet retained cheek plumper in complete denture esthetics: a case report. J Dent (Tehran), 2014;11(1):100-105.

[6] Bhushan P, Aras MA, Coutinho I, Rajagopal P, Mysore AR, Kumar S. Customized Cheek Plumper with Friction Lock Attachment for a Completely Edentulous Patient to Enhance Esthetics: A Clinical Report. J Prosthodont, 2019 Jan;28(1):e1-e5.

[7] The Glossary of Prosthodontic Terms: Ninth Edition. J Prosthet Dent, 2017 May;117(5S):e1-e105.

[8] Clair F, Picard Complete denture esthetics. J Prosthet Dent, 1958 Mar;8(2):252-9.

[9] Virdiya NM, Palaskar JN, Wankhade J, Joshi N. Detachable cheek plumpers with different attachments for improving esthetics in a conventional complete denture: A clinical report. J Prosthet Dent, 2017 May 1;117(5):592-6.

[10] Vande A, Kore A, Sanyal P, Nilesh K. Customized attachment retained hollow cheek plumper to enhance esthetics in elderly: report of a novel technique. Int J of Contem Med Res, 2019;6(6):F11-F13.

[11] Venkatachalapathy SR, Chander GN, Gnanam P. A magnetically retained cheek plumper in a maxillary single complete denture: A clinical report. J Interdiscip Dentistry, 2019;9:25-30.

[12] Kumar D, Rajeswari CL, Srivatsa G, Shetty RM. Hooks retained detachable Cheek plumper to enhance aesthetics in a completely edentulous patient-A case report. Int Jour of Oral Heal Dent. 2019;5(3):136-9.

[13] Rewari A, Dabas N, Sanan R, Phogat S, Phukela SS, Vigarniya M. Esthetic Rehabilitation Using Magnet-Retained Cheek Plumper Prosthesis. Case Rep Dent, 2020;2020:2769873.

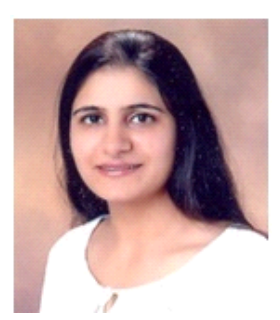

Dr. Manu Rathee was born on 06/09/1973 in India. Degrees - Master of Dental Surgery (Prosthodontics) (1998-2001) and Bachelor of Dental Surgery (1991-1996) from D.A.V. (Centenary) Dental College, Yamuna Nagar, Haryana, India.

Presently, she is the Senior Professor \& Head of the Department, Department of Prosthodontics, Post Graduate Institute of Dental Sciences, Pt. B.D. Sharma University of Health Sciences, Rohtak, Haryana, India. Previously she worked as an Associate Professor in M.M. College of Dental Sciences \& Research, M.M. University, Mullana (Ambala) Haryana.

She has published articles in reputed journals as below:

1. Rathee M. Effect of Platelet Rich Fibrin (PRF) on Peri-implant Soft Tissue and Crestal Bone in One-Stage Implant Placement: A Randomized Controlled Trial. Journal of Clinical Diagnostic Research, 2015;9(4):ZC18-ZC21.

2. Rathee M. Single visit feeding appliance for 1-day-old neonate with cleft palate using safe dental putty-gauze hybrid impression technique for maxillary impression. Journal of Surgical Technique and Case Report, 2015;7:7-11.

3. Rathee M. Bisphenol A in Dental Sealants and its Estrogen like Effect: A Review. Indian Journal of Endocrinology and Metabolism, 2012:16(3);339-42.

She is the Founder President in Indian Prosthodontic Society, Haryana State Branch. She has served as Executive Council Member of Indian Prosthodontic Society and Central Council Member of Indian Dental Association.

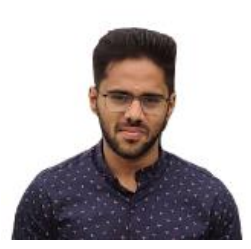

Dr. Divakar S was born on 17/04/1995 in India. Degree - Bachelor of Dental Surgery (2012-17), The Tamilnadu Dr. MGR medical university, Chennai India. He worked as Junior Resident (Non-acad) in All India Institute of Medical Sciences (AIIMS), New Delhi, India for eight months (2019 and 2020). Presently, He is a Post graduate trainee (Master in Dental Surgery) in Department of Prosthodontics, Post Graduate Institute of Dental Sciences, Pt. B.D. Sharma University of Health Sciences, Rohtak, Haryana, India. He has published articles in some reputed journals as below:

1. Role of diabetes in the prosthodontic management of a completely edentulous patient. International Journal of Dental Research, 2020;3. 50-52.

2. Prosthodontic implication of nerves of orofacial region- A review. Asia Specific Dental Journal, 2021;8(3): 20-25.

3. Preventive prosthodontics for management of partial edentulous: A case report. Asia Specific Dental Journal, 2021;8(3): 16-19.

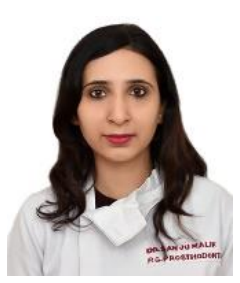

Dr. Sanju Malik, was born on 30/07/1991 in India. Degree- Master in Dental Surgery (Prosthodontics) from Post Graduate Institute of Dental Sciences, Rohtak, Haryana, India (2016-2019) and Bachelor of Dental Surgery from SGT Dental College, Haryana, India (2009-2014). She is currently working as Senior Resident in Department of Prosthodontics, Post Graduate Institute of Dental Sciences, Pt. B.D.Sharma University of Health Sciences, Rohtak, Haryana,

India.

She has published articles in some reputed journals as below:

1. 3-D printing an upcoming technology in prosthodontics. Guident. 2019.

2. Resilient customized hollow vaginal stent for the treatment of vaginal agenesis in Mayer-Rokitansky-Kuster-Hauser syndrome. Nigerian Journal of Surgery, 2019; 11(2):32-35.

3. Basal implants for geriatric patients. Journal of West Bengal University Health Sciences, 2020;1(1)91-95.

She is currently the Executive Council Member of Indian Prosthodontic Society, Haryana state branch.

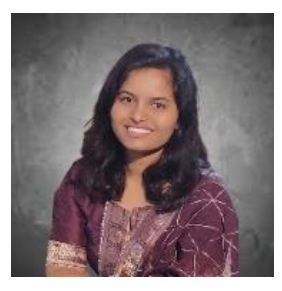

journals as below:
Dr. Poonam Wakure was born on 8/4/1994 in India Degree - Bachelor of Dental Surgery (2012), Government Dental College, Aurangabad, Maharashtra, India. She is presently a Post graduate trainee (Master in Dental Surgery) in Department of Prosthodontics, Post Graduate Institute of Dental Sciences, Pt. B.D.Sharma University of Health Sciences, Rohtak, Haryana, India. She has published articles in some reputed 
1. Comparative evaluation of crestal bone level in patients having low level of Vitamin D treated with dental implant with or without Vitamin D3 supplements. National Journal of Maxillofacial Surgery, 2019, 11 (2),199-206.

2. Rehabilitation of an Edentulous Patient with Flabby Ridge Using Modified Window Technique - A Case Report. Journal of Dentistry \& Oral Disorders, 2020; 6(6): 1149.

3. Preventive Prosthodontics for management of partial edentulism: A case report. Asia Pacific Dental Journal, 2021, 8, (3), 16-19.

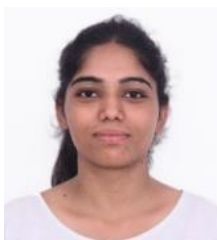

Dr. Sujata Chahal was born on 08/01/1995 in India. Degree - Bachelor of Dental Surgery (2013), Post Graduate Institute of Dental Sciences, Pt. B.D.Sharma University of Health Sciences, Rohtak, Haryana, India. She worked as Junior Resident (Non-acad) in Government Medical College and Hospital Chandigarh for five months (Jan 2020 - May 2020). Presently, she is a Post graduate trainee (Master in Dental Surgery) in Department of Prosthodontics, Post Graduate Institute of Dental Sciences, Pt. B.D. Sharma University of Health Sciences, Rohtak, Haryana, India. She has published articles in some reputed journals as below

1. Role of diabetes in the prosthodontic management of a completely edentulous patient. International Journal of Dental Research, 2020;3. 50-52.

2. Prosthodontic implication of nerves of orofacial region - A review. Asia Specific Dental Journal, 2021;8(3): 20-25. 